\title{
新时代我国自然资源综合科学考察研究的 挑战与展望
}

\author{
孙九林 ${ }^{1,2}$, 董锁成 ${ }^{1,2}$, 李泽红 ${ }^{1,2}$, 李 宇 ${ }^{1,2}$, 李富佳 ${ }^{1,2}$ \\ (1. 中国科学院地理科学与资源研究所, 北京 $100101 ; 2$. 中国科学院大学, 北京 100049)
}

\begin{abstract}
摘要：自然资源综合科学考察是基础性科技工作,对于服务国民经济和社会发展具有重要的 科技支撑作用。进人 21 世纪, 我国自然资源综合科学考察工作从低谷中逐步复苏, 但依然面临 科考人才断档、经费支持不足、跨国考察组织艰难、重大成果产出不多等诸多挑战。本文从地 域范围、队伍组成、技术手段、成果影响等角度总结了我国综合科学考察工作的最新进展, 并展 望新时代, 提出了我国综合科学考察研究工作的六大发展趋势, 包括: 从综合科学考察向自然 资源综合考察研究转变; 考察国际化进程将加快; 注重多学科综合考察与宏观微观结合调查; 考察技术将更加多样化、智能化和精准化; 考察信息数据共享平台支撑能力更加强大; 科考人 才的培养成为紧迫需求将得到加强。
\end{abstract}

关键词: 自然资源; 综合科学考察; 新时代;进展; 挑战; 展望

自然资源综合科学考察是指利用现场调查、定点观测、遥感监测、科学实验等多种 方法，对区域自然资源数量、质量、分布、潜力及环境条件开展多学科本底数据和材料 的获取、整理与编研的过程，是基础性科技工作，对指导各阶段区域开发和资源科学综 合研究都具有不可替代的科技支撑作用。70年来，我国自然资源综合科学考察研究工作 大致经历了大规模的自然资源综合考察时期（1950-1970年）、区域资源综合科学考察 与研究时期（1970-1990年）、自然资源综合科学考察研究低谷期（1990-2005年）和 多学科综合科学考察研究时期（2005-2020 年）。2 1 世纪以来，在科技部、中国科学院 （以下简称中科院）等部门的大力支持下, 我国自然资源综合科学考察研究工作在广度和 深度上不断拓展, 取得了一些标志性进展。迈人新时代, 新的发展环境对自然资源综合 科学考察研究工作提出了新的历史使命。本文在总结我国自然资源综合科学考察工作最 新进展和面临挑战的基础上, 结合我国新时代新需求，展望新时代我国自然资源综合科 学考察研究工作的几个重要发展趋势。

\section{1 进展}

近 20 年来, 我国自然资源综合科学考察研究工作从低谷中逐步复苏, 在考察地域范 围、队伍组成、技术手段、成果影响等方面都取得一定进展（图 1)。中国北方及其毗邻

收稿日期：2020-06-21; 修订日期：2020-07-06

基金项目：国家科技基础资源调查专项（2017FY101300）；第二次青藏高原自然资源综合科学考察研究任务子专题 (2019QZKK040303)

作者简介：孙九林（1937- ), 男, 江苏盐城人，博士，研究员，博士生导师，中国工程院院士，·主要从事资源环境 信息化管理与应用研究。E-mail: sunj1@igsnrr.ac.cn

通讯作者: 董锁成 (1962- ), 男, 甘肃平凉人, 博士, 研究员, 博士生导师, 俄罗斯自然科学院通讯院士, 主要从 事资源经济和区域生态经济研究。E-mail: dongsc@igsnrr.ac.cn 


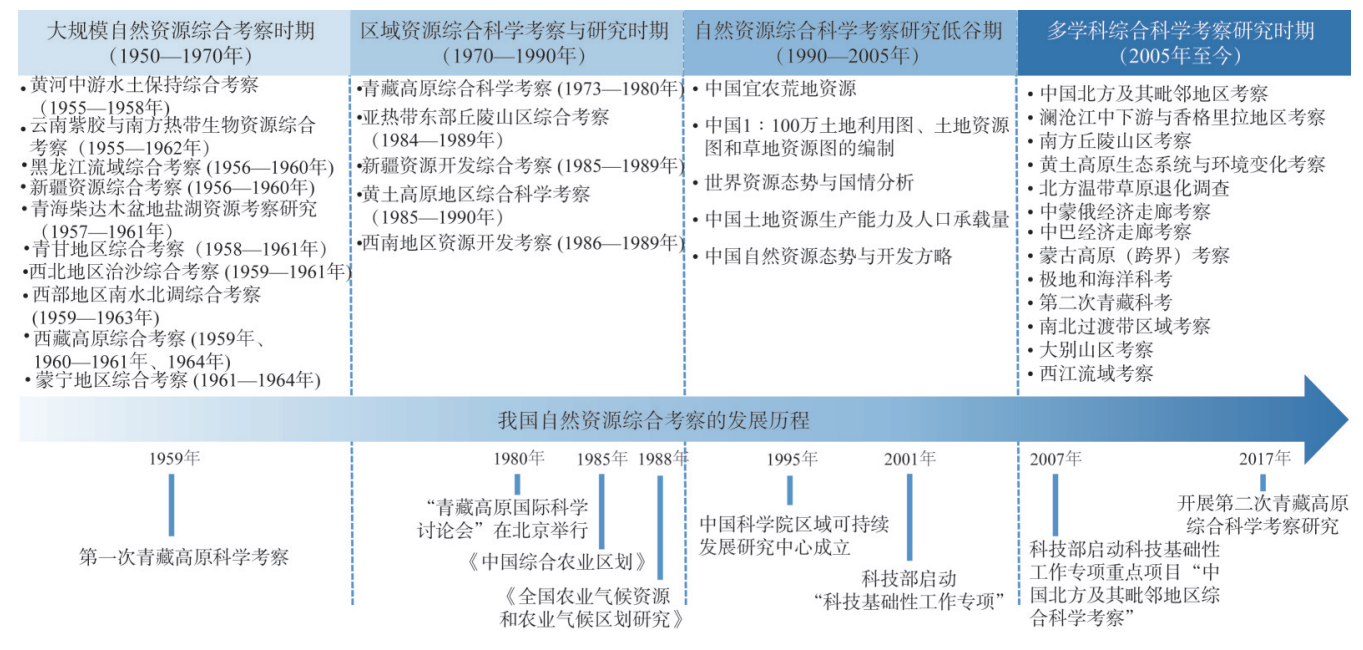

图 1 我国自然资源综合考察发展历程

Fig. 1 Development process of the integrated surveys of natural resources in China

地区考察、澜沧江中下游与大香格里拉地区考察重启了我国中断近半个世纪的跨国科学 考察，中蒙俄经济走廊、中巴经济走廊、蒙古高原（跨界）等考察工作则把我国跨国科 学考察研究引向深人，提升了我国科学认识跨境区域的能力; 极地和海洋科考全力推 进, 助推我国极地海洋科学缩小与发达国家的差距; 在党和国家领导人的亲切关怀下, 第二次青藏科考启动实施, 继续助推我国青藏高原科学研究领跑世界; 南北过渡带、大 别山区、西江流域等一批特定区域考察工作的陆续开展，重启了国内重点区域综合考察。 这些考察研究工作对指导我国区域开发、资源环境保护、生态文明建设和推进 “一带一 路”倡议实施起到重要的基础科技支撑作用。

\section{1 考察地域范围大为扩展,三极并进,由个别周边国家走向世界五大洲}

青藏高原综合科学考察工作的国际化影响持续加大。从 20 世纪 50 年代初至 21 世纪 初, 我国开展了第一次青藏高原科学考察。1980年在北京举行“青藏高原国际科学讨论 会”，开始了国际合作研究青藏高原的新局面 ${ }^{[1-3]}$ 。2017年3月，中科院和西藏自治区确定 共同开展我国第二次青藏高原综合科学考察研究, 此次科考由中科院青藏高原研究所牵 头, 协调全国力量, 联合国际伙伴共同展开。2017年 8 月 19 日，可近平总书记发来贺信 并作出重要指示：开展这次科学考察研究，揭示青藏高原环境变化机理，优化生态安全 屏障体系，对推动青藏高原可持续发展、推进国家生态文明建设、促进全球生态环境保 护将产生十分重要的影响 ${ }^{[4]}$ 。第二次青藏科考的主要目标是关注在全球变暖的背景下，青 藏高原水循环和生态及生物多样性的重大变化 ${ }^{[5]}$ 。

南极和北极地区科考工作全力推进。从 1980 年代至今, 我国已陆续开展南极洲科学 考察共计 33 次, 建立了 4 个科学考察站, 在深冰芯钻探、地貌调查、地面环航、航空测绘 研究领域取得丰富的成果, 积累了丰富的科研基础数据 ${ }^{\left[{ }^{6}\right]}$ 。共开展北极地区科学考察 9 次, 其中第 9 次考察为 2018 年 7 月 20 日至 2018 年 9 月 26 日，历时 69 天，雪龙船总航行约 12500 海里, 冰区航行 3815 海里, 最北到达 $84^{\circ} 48^{\prime} \mathrm{N}^{[7]}$ 。此次科学考察与国际北极漂流冰 站计划、国际极地预报年等国际极地考察和研究计划相配合, 探索了北极海洋酸化、微 塑料和人工核素等热点海洋环境问题，首次应用了自主研发的 “无人冰站”、水下滑翔机 
及爬升式海洋剖面浮标等观测设备。我国开展的极地科学考察有助于全球变化、南极北极 生态保护研究，有助于为今后全球可持续发展及人类生存发挥预警性启示提供科技支持。

2000 年至今，在科技部、中科院等相关部门支持下，在中科院院士孙鸿烈、陈宜 瑜、姚檀栋、中国工程院院士李文华、孙九林、中国科协原副主席刘恕、中科院国际学 术交流中心高级工程师陶宝祥等指导下, 中科院地理科学与资源研究所、青藏高原研究 所、新疆地理与生态研究所等科研机构和相关高校的科学家, 联合俄罗斯科学院、蒙古 科学院以及中亚、南亚等国外科研院所的科学家开展了北极、“泛第三极”、亚马逊、贝 加尔湖、中亚大湖区和 “古丝绸之路”、东非大裂谷、撒哈拉沙漠和尼罗河、澳大利亚沙 漠、湄公河等地区的科考活动（图 1、图 2)，对上述区域的资源、环境、生态和社会经 济与文化等进行了综合考察，为探索不同区域可持续发展模式和 “一带一路” 建设提供 了基础科学支撑 ${ }^{[8]}$ 。

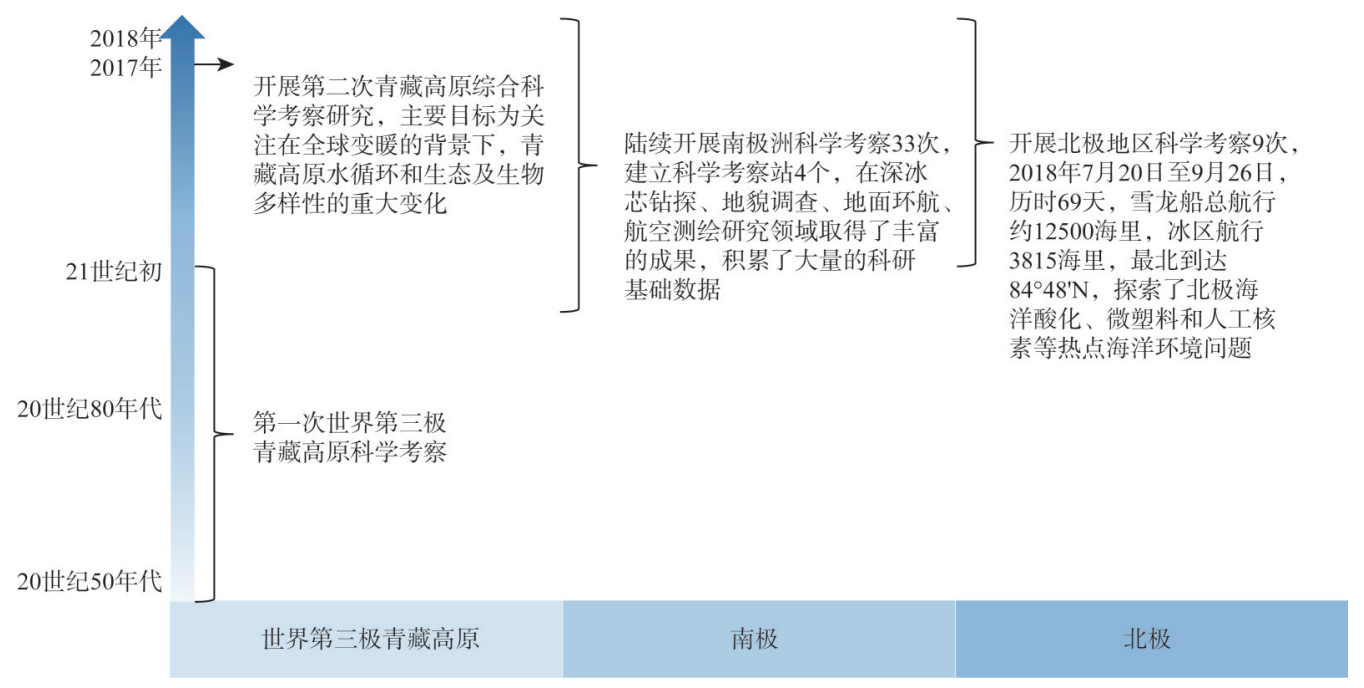

图 2 全球重点区域自然资源综合科学考察

Fig. 2 Integrated surveys of natural resources in key regions across the globe

\section{2 考察队伍由国内专家转向以我国为主,多国联合考察共同推进}

由于条件和认识的限制, 我国自然资源综合科学考察活动多年来一直仅在国土范围 内进行, 且大多由国内专家组成, 探索地区的区域发展及地域的地理环境、人文和经济 发展概况。2 1 世纪以来，随着全球化的推进，可持续发展理念的不断深人，如何清楚地 认识本地区区情, 发挥地理区位与资源禀赋优势, 更好地为各国的发展提供支撑, 建立 和完善经济大通道等问题，成为了科学考察的重要任务。在这些因素的共同推动下，考 察队伍逐渐由国内专家为主的传统考察方式转向以我国为主、多国联合共同推进的模 式, 进行大规模、多国、多学科的综合科学考察。2005-2020年, 在俄罗斯科学院资深 院士 Mikhail Kuzmin、Arnold Tulokhonov、Peter Baklanov 和蒙古科学院资深院士 Dechingungaa Dorjgotov等外籍科学家的大力支持下，中俄蒙科学家联合持续开展了中国北方及 其毗邻俄罗斯、蒙古中高纬度地区多学科的综合科学考察，为东北亚地区可持续发展和 全球气候变化研究提供了重要的科学基础数据。

在国际科学考察发展过程中, 国内外学者之间的积极互动, 使相关学术研究和学术 
活动活跃起来。在数年时间里, 各大科研机构和高校均举办了不同规模的学术会议, 专 门探讨各领域相关的科学问题, 产生了大量的学术研究成果。随着学术研究的不断深 人，围绕建设目标的各种战略构想、项目设计、政策建议和技术碰商不断出现。

\section{3 考察技术手段由传统实地调查转向“3S”信息技术、国际信息网络和 E-Science 技术与 实地考察、定位观测等技术方法相结合}

随着国内科学技术手段的不断成熟，我国的考察技术手段正在由传统的实地调查逐 步向以 “3S” 信息技术为主的国际信息网络和 E-Science 技术与实地考察、定位观测等技 术方法相结合的方向转变。

2007 年科技部正式启动科技基础性工作专项重点项目 “中国北方及其毗邻地区综合 科学考察”，该项目在综合科学考察的国际化、信息化、数字化、标准化、规范化、智能 化、定位监测和数据共享等领域科技创新取得了突破性进展，表现在以下几个方面：第 一, 提出并实施中国北方及其毗邻地区综合科学考察点一线一面一网推进，定点观测、 综合调查、数据集成、样带分析、国际协同创新信息平台和国际科学家联盟的技术方 案, 解决了多学科、多尺度、跨区域、全要素、大规模国际科学考察的技术难题; 第 二, 系统建立国内规模最大、学科最多、覆盖面积最广的中蒙俄跨境区域数据库群、地 图集和样品标本库，填补了我国近几十年来在该地区的资料空白; 第三，在国际上首次 尝试构建东北亚南北生态样带; 第四, 制定 16 项综合科学考察标准规范并在科学考察中 示范应用; 第五, 与俄蒙科研机构签署协议 10 余项; 第六, 创建 E-Science数据共享与交 流网络平台; 第七, 出版了 10 部科学考察专著, 发表了 100 多篇论文; 第八, 考察成果 除传统科技资源、信息等成果外，还同国外合作单位共建共享野外生态实验站、定位观测 点, 为我国今后系统研究俄蒙地区资源开发利用和区域可持续发展奠定了坚实的基础 ${ }^{[9,10]}$ 。

2008年科技部启动国家科技基础性工作专项重点项目 “澜沧江中下游与大香格里拉 地区科学考察”，该项目是我国首次在流域尺度上开展的多学科、多尺度、大范围的综合 科学考察, 范围涉及中国西南地区与中南半岛毗邻地区。通过点、线、面结合, 遥感监 测、实地调查与样点分析相结合, 对考察区水资源与水环境、土地利用与土地覆被、生 物资源及生物多样性，生态系统本底与生态服务功能、山地地质灾害、人居环境、民族 文化等开展了调查。项目在综合集成多源科学数据的基础上，揭示了澜沧江流域与大香 格里拉地区的自然资源、生态环境和社会经济梯度变化规律, 科学评估了气候变化及水 电开发、矿产资源开发、产业发展等人类活动对区域水土资源、生态环境、生态系统服 务功能、人居环境的影响以及山地灾害的敏感性, 提出了需要进一步深人研究的若干科 学问题 ${ }^{[1]}$ 。

\section{4 “一带一路”倡议后科学考察逐渐向“一带一路”沿线国家和六大经济走廊扩展, 除服务 基础研究需求外还面向社会经济发展需求}

2013年9月和 10 月，国家主席习近平在出访中亚和东南亚国家期间，先后提出共建 “丝绸之路经济带” 和“21世纪海上丝绸之路”（以下简称 “一带一路”) 的重大倡议, 得到国际社会高度关注。2015 年3月，国家发展改革委、外交部、商务部发布《推动共 建丝绸之路经济带和 21 世纪海上丝绸之路的愿景与行动》, 明确提出沿线资源禀赋各 异、经济互补性较强的各国, 彼此合作潜力和空间很大 ${ }^{[12]}$ 。迄今为止, 全球 100 多个国家 和国际组织积极支持和参与 “一带一路” 建设, 联合国大会、联合国安理会等重要决议 也纳人 “一带一路” 建设内容 ${ }^{[13]}$, 开展中蒙俄、新亚欧大陆桥、中国一中亚一西亚、中 
国一中南半岛、中巴、孟中印缅六大经济走廊建设。

目前“一带一路”沿线和六大经济走廊国家地理环境背景不清，资源和市场潜力不 明，经济活动和城市化对于脆弱生态环境影响巨大，经贸合作重点领域及重点区域投资 环境模糊，迫切需要系列基础科技数据资源，为 “一带一路” 开展经济合作、生态合 作、资源环境合作等提供科学决策支持。但由于沿线国家资源环境、社会经济数据统 计、采集标准、管理技术规范等概念语义存在不同，为跨国多学科联合科学考察及其获 取数据的集成、共享和利用带来直接障碍，建立适合于六大经济走廊的区域性统一标准 和规范、联合科学考察与信息共享的机制与平台是 “一带一路” 科学家联合开展国际跨 国境科学考察的现实迫切需求。

2017 年科技部正式启动科技基础资源调查专项 “中蒙俄国际经济走廊多学科联合科 学考察” 项目，在该项目资助下，中蒙俄三国科学家联合开展了多次大型综合科学考 察，对中蒙俄国际经济走廊区域的地理环境格局、自然资源、社会经济、投资环境、城 市化与基础设施等领域进行了综合科学考察研究，倡导绿色经济走廊理念，联合组织召 开了 IGU 主题会议 “一带一路”与欧亚经济联盟特别论坛、“一带一路” 国际科学家联盟 智库论坛、蒙古高原可持续发展国际研讨会等国际会议，联合建立了沙漠化防治技术示 范站、冻土灾害防治示范点，对于促进中俄蒙三国科技交流、资源环境国际合作、应对 全球气候变化，以及中蒙俄经济走廊绿色发展具有重要的科学和实践意义。

\section{2 时代需求}

新时代，我国实现现代化两阶段目标和中华民族伟大复兴，在多极化的全球格局中 承担更多的全球治理责任，不断推动人类命运共同体建设，对我国自然资源综合科学考 察研究工作提出了新的需求 ${ }^{[14]}$ 。

\section{1 亟需拓展全球重点区域自然资源综合科学考察研究}

如何充分利用好国际、国内“两种资源” “两个市场”，全面提升全球治理能力，是 新阶段我国面临的重要任务。因此, 亟需通过开展国际自然资源综合科学考察研究, 全 面获取和科学评估全球资源、市场、地缘环境等信息，尤其是亟待开展围绕 “一带一 路” 沿线地区、全球治理关键地区、全球重要海域等自然资源综合科学考察研究。

\subsection{1 积极开展以“一带一路”为重点的跨境自然资源综合科学考察研究}

新时代，我国“一带一路”倡议进人深度推进和落实的关键阶段，其推进效果直接 关系到我国各项战略目标的实现和人类命运共同体的建设 ${ }^{[15]}$ 。目前对 “一带一路” 沿线 大部分国家和区域的生态环境本底及变化情况、资源赋存及开发利用状态、经济社会发 展和文化风情及驱动因素等仍然了解不深，数据不足，无法适应推进 “一带一路” 五通 建设的实际需求。因此，亟待全面开展以“一带一路” 沿线重点地区为核心的跨境自然 资源综合科学考察，全面摸清 “一带一路” 沿线生态、环境、资源、经济社会发展等多 方面本底数据信息，补足我国对 “一带一路” 沿线地区战略信息严重缺失等短板，更好 地服务沿线发展。

\subsection{2 加强针对全球治理关键地区的自然资源综合科学考察研究}

作为新时代负责任的大国，我国将进一步承担全球治理责任，深度参与在应对全球 气候变化、保护全球生态环境、维护世界和地区和平、推动全球可持续发展目标实现等 
各类关键领域的全球治理工作。这在客观上需要我国对全球地缘政治、经济、生态、安 全关键区域具备更进一步的了解。因此，亟需开展针对全球地缘政治敏感区、生态环境 脆弱区、区域冲突易发区、自然灾害频发区、公共卫生风险区等全球治理重点区域的自 然资源综合科学考察研究, 如东北亚地区、中亚及东欧地区、波斯湾地区、极地周边地 区、太平洋岛链地区等，为我国建立全球综合风险预警体系、应对全球重大突发事件、 提升全球治理能力提供重要支撑。

\subsection{3 积极推动全球重要海域自然资源综合科学考察}

近年来，海洋对全球地缘经济政治格局的影响日渐重大。海洋资源开发利用对人类 未来资源安全和可持续发展影响深远、海上通道制约全球战略物资流通及地缘政治安 全、海洋生态影响全球气候变化与生态系统平衡。新时代, 国际经贸活动的开展、全球 治理的实施、地缘安全的保障、重大国际争端的解决, 都离不开对海情海况及海域地缘 环境的深度了解 ${ }^{[16]}$ 。全面掌握全球海洋综合信息对提升我国远洋能力和全球治理能力具 有重要意义。因此, 亟需开展针对我国领海及周边海域、全球关键海上运输通道、重要 海港及岛屿、重点湾区城市群等重要海域的资源、生态、地缘环境等综合科学考察工作。

\section{2 亟需开展国内重要生态地理单元自然资源综合科学考察研究}

新时代, 全球气候变化趋势的加剧, 对我国区域生态系统演化、生态功能完善、生 态安全保障形势产生重大影响。面向新的生态安全形势和可持续发展需求, 习近平总书 记提出了建设生态文明、“两山论” “山水林田湖生命共同体” 等一系列指导思想和重大 战略。这些重大战略的实施, 亟需针对我国大江大河、高原山脉、海洋、湖泊以及重要 生态保护区、人文要素、地理分界线等关键生态地理单元开展新一轮更全面、深人的自 然资源综合科学考察, 如目前已部署开展的青藏高原、新疆等综合科学考察等, 为保障 我国生态安全和推进生态文明建设奠定坚实基础。

\section{3 亟待推进人类活动新领域探索性综合科学考察}

随着科技的进步，极地、深海、深空等传统意义上人类活动较少涉足的区域已逐渐 成为新时代人类探索的前沿领域和潜力地区，对这些区域的探索成果，将对未来全球地 缘格局演化和人类生存发展产生重大影响。北极、南极及以青藏高原为核心的泛 “第三 极”地区资源储量巨大、地缘战略位置重要、生态环境特征独特，对未来全球气候变 化、生态环境地质演化、生物多样性进化以及地缘战略格局变迁等具有重要且深远的影 响。而我国航天技术的发展和蛟龙号等深海探测技术的不断突破，也使深海、深空探索 逐渐成为我国自然资源综合科学考察的巨大潜力空间。因此，在扎实推进各项基础性综 合科学考察工作的同时，也应聚焦科技前沿，提前布局开展针对极地、深海、深空等人 类活动新领域、新区域的自然资源综合科学考察。

特别是近年来，在全球气候变暖趋势影响下，北极海冰融化及其带来的全球性生态 影响日渐凸显, 也使北极航线的开发成为可能, 而北极航线将极大地改变全球海运格 局，进而对全球战略资源流动、开发利用格局，乃至全球地缘战略格局带来重大影响。 围绕北极地区的开发和探索已引起了俄罗斯、美国、欧盟诸国等北极国家的高度关注， 纷纷出台了针对北极地区的科学考察、资源勘查与开发战略 ${ }^{[17]}$ 。我国作为北极事务的正 式国际观察员国家，应尽早开展围绕北极及泛北极区域的综合科学考察和相关国际合作 研究, 为未来联合开发北极资源、打通我国远洋北极航道、构建冰上丝绸之路奠定坚实 
的数据基础。

\section{3 挑战与展望}

\section{1 面临的挑战}

近 20 年来，我国综合科学考察工作经历了从低谷到复苏的过程，在科技部资助下启 动的一批国家科技基础性工作专项和国家科技基础资源调查专项，助推我国近年来在国 内外科学考察方面取得了一定的进展，在党和国家领导人的亲切关怀下，2017年启动的 第二次青藏高原科考是我国新时代综合科学考察工作复苏的重要标志和里程碑事件。但 是回首我国自然资源综合科学考察工作的光辉历史，对标新时代现代化建设和民族复兴 对科考工作的客观要求，当前我国自然资源综合科学考察工作任重道远，面临的挑战依 然巨大。

\subsection{1 科考专业人才的断档}

1980 年代末，国家组织的全国性大规模科学考察工作基本结束，1990年代至 21 世纪 之初, 全国性的自然资源综合科学考察工作基本中断, 加上国内科考工作的领军单位中 国科学院和原国家计划委员会下属的自然资源综合考察委员会因为机构改革，部分科考 人员转岗和退休, 致使目前国内科考人才队伍青黄不接, 这直接影响自然资源综合科学 考察研究事业的延续。国际科学考察人才尤为短缺, 复合型科学考察人才严重不足, 语 言障碍、交流不畅、专业素养、野外工作能力、敬业精神、组织协调能力不足等都严重 影响科学考察质量和效果。所以, 在当前和今后很长一段时期都必须高度重视科考人才 的培养，大力培养优秀中、青年科考骨干，建立一支高水平的科考工作 “国家队”，尽快 缓解和解决我国科考工作后继乏人这一突出问题。

\section{1 .2 跨国科考工作十分艰难}

科学考察历来就是十分敏感的工作，如果得不到考察区域政府和科研部门的支持, 跨国科考将寸步难行。同时，跨国科学考察环境复杂，条件艰苦，困难较多，不确定性 大, 多国联合考察组织困难。此外, 跨国科学考察安全风险挑战较大, 包括人身安全风 险、保密风险、民族宗教习俗和法律法规及外交安全风险等。近年来我国与邻国的联合 科学考察也多局限于应对全球气候变化、灾害风险调查与生态环保跨境合作等共同关注 的领域，在涉及到核心利益的领域很难涉足。在全球贸易保护主义抬头，逆全球化思潮 影响下，一些考察工作受到西方国家排挤，尤其是在南北极、深地、深空、深海 “两极 三深” 领域的跨国科学考察和探测工作很难开展。应该说，“一带一路”倡议背景下，当 前是国际合作机遇期，机不可失，必须把握机遇，及时部署，由中国科学家为主导，启 动一批跨国科考项目或国际科考计划，促进科学考察工作的国际化。通过任务带动，推 动我国科学家积极参与国际科技组织, 提升我国科技界在国际科学共同体中的地位。

\section{1 .3 科考经费保障挑战}

1990-2005 年是我国自然资源综合科学考察工作的低谷期，时逢国家系列大型科考 任务相继结束，国家科考领军机构改制，新的国家级科考任务少有下达，科考经费明显 萎缩。在这一背景下，一批对科考工作具有特殊情怀的科学家、探险家、企业家走在一 起，他们积极申请企业赞助、国际组织资助等各类社会资助，积少成多，以有限的资金 组织了一系列颇具特色的科考工作，引起社会广泛关注，并取得了几项不可多得的科考 
成果，堪称我国科考界的奇迹。比如由原国家林业局、青海省政府、中国科学院、中国 探险协会组织的三江源综合科学考察（2000年，天津天士力制药股份有限公司资助）, 形成的咨询报告得到党和国家领导人批示，促成了我国三江源自然保护区的建立; 雅鲁 藏布江科考（1998 年，珠海天年科技有限公司资助）、北极地区科考（2000-2001 年， 湖南新大新集团、新疆伊力特酒业有限公司资助）、贝加尔湖科考（2005 年，中新药业 集团股份有限公司资助）、亚马孙流域科考（2004 年，中新药业集团股份有限公司资 助）等工作的开展，在国内外引起巨大反响，中央电视台对这些考察工作都进行了系列 跟踪报道。正是在 2005 年中俄贝加尔湖科考的基础上，2007年科技部下达了我国第一个 跨境科学考察专项 “中国北方及其毗邻地区综合科学考察”。不得不说，社会资助成为这 一时期科考经费的重要来源, 并在世纪之交的过渡时期为我国科考工作的延续发挥了 “雪中送炭” 的作用，为我国科考事业的延续做出了贡献。但社会资助具有极强的不确定 性，近年来，社会资助的大型科考工作明显减少。而与此同时，国家科技主管部门每年 下达的科学考察类专项经费总和较低, 国际科学考察经费预算更是不足, 实际支出往往 超过预算，经费管理规定限制了经费在国际间划拨，影响国际联合考察顺利进行。有关 科技主管部门必须从增强国家自主创新能力和创新型国家建设的高度，进一步提高对科 考类科技基础资源调查工作的认识，加强科考工作系统部署，稳定支持，不断积累，持 续发展。

\section{1 .4 重大科考成果产出不多}

1970-1990年代，国家组织的系列综合科学考察工作，取得了一批重大科学考察成 果，比如青藏高原综合科学考察（1973-1980年）、亚热带东部丘陵山区综合考察 （1984－1989年）、新疆资源开发综合考察（1985-1989年）、黄土高原地区综合科学考 察（1985-1990年）与西南地区资源开发考察（1986-1989年）等资源开发与区域发展 大型综合考察研究工作, 先后出版了中国亚热带东部丘陵山区考察丛书32册、黄土高原 考察丛书 46 册、新疆地区考察丛书 21 册和西南地区考察丛书 28 册及其他若干区域性、 专题性著作, 为区域资源开发与经济发展提供了重要科学依据 ${ }^{[18,19]}$ 。这些工作不仅查清了 考察区 “资源家底”，而且提出资源合理开发和保护方案，为资源开发利用、国民经济发 展和国土整治发挥了重大作用，培养了一大批科考人才，积累了丰硕成果，为青藏高原 科学和资源科学发展奠定了坚实的基础。其中青藏高原综合考察成果获得了全国科学大 会奖。但因种种原因，当年一些好的做法没有延续下来。相比那一时期，近 20 年重大科 考成果产出不多, 尤其缺乏显示度高的新成果，成为新时代我国科考工作不得不面对的 现实问题。

\section{1 .5 科考工作成果价值得不到认可}

科考工作较多涉及野外科技工作，面向大自然，工作条件较为艰苦，不容易发表论 文，显示度一般也不高。在当前科技管理体制下，科研院所的考评体系中，对科学数 据、基础图件、整编资料等基础性科研成果的认可度不高，排序往往大幅落后于获奖、 SCI 论文、专利等显性成果。这使得科考研究人员的价值得不到体现, 野外考察工作往 往是 “苦差” “累活”, 难以吸引最优秀的人才和团队积极参与。加快制定与科学考察工 作特点相适应的成果评价机制和激励政策，提升科考成果在科研院所考评体系中的地位 变得尤为重要。 


\subsection{6 科考工作的自信缺失}

经历一段时期的科考工作低谷期后，一批科考工作者开始怀疑科考工作的价值，对 科考工作失去信心。有的同志甚至明确提出, 靠科学考察产出重大科研成果的时代一去 不复返了。“科考无用论” 在某些地理学家、资源学家的脑海里是客观存在的。为此, 我 们建议将科考工作与资源科学、地理科学等学科研究工作紧密结合起来, 从纯科考工作 向科考综合研究转变, 提升科学考察工作服务解决前沿科学问题和服务国民经济主战场 的能力。

\section{2 未来展望}

新时代是实现中华民族伟大复兴，与世界携手构建人类命运共同体的重要历史时 期，我国科学事业也将经历更加深刻的变革。自然资源综合科学考察研究作为人类认识 自然、了解自然和深人研究自然资源的基础性科研工作，也将面临新的机遇与挑战。一 方面中华民族伟大复兴的紧迫性需要科学考察工作既要面向世界科学前沿，又要服务我 国国民经济建设主战场, 推进科学考察工作向自然资源综合研究工作转变, 提高科学考 察研究工作的深度; 另一方面构建人类命运共同体, 亟待科学考察工作向广度进军, 迈 出国门, 拓展全球领域, 推进多学科交叉研究。此外, 日新月异的地球科学、信息科 学、生命科学、工程科学等多学科领域技术创新, 将极大地促进自然资源综合科学考察 技术变革，为科学考察工作向广度、深度和精度进军创造了条件。展望新时代，我国自 然资源综合科学考察工作将呈现出以下特征:

\section{2 .1 从综合科学考察向自然资源综合考察研究转变}

近 70 年来, 我国科学考察工作取得了显著成就，尤其是 20 世纪 60 年代至 90 年代, 我国基础性的科学考察工作几乎覆盖国土大部分区域，为指导新中国国土开发奠定了 良好的科学数据基础。新时代的自然资源综合科学考察工作绝不会简单重复先前考 察工作，而是将在前期科学考察工作的基础上，更加强调面向国民经济主战场和国 家战略需求，开展更加深人、更加全面的自然资源综合考察研究，更好地服务国家 重大战略。2000 年以来，科技部 “科技基础性工作专项” 启动一批重大科学考察工 作。2017年，科技部在原 “科技基础性工作专项” 基础上，重新整合设立 “科技基础资 源调查专项”，专项指南中指出科技基础资源调查，是指面向科学目标和国家战略需求开 展的对自然本底数据和材料的获取、对已有数据和材料的整理与编研等科技基础性工 作，具有基础性、公益性、系统性等特征 ${ }^{[20]}$, 首次强调了科技基础资源调查项目需要服 务国家重大战略。2017年习近平主席在《致中国科学院青藏高原综合科学考察研究队的 贺信》中明确提出, 希望考察工作聚焦水、生态、人类活动，着力解决青藏高原资源环 境承载力、灾害风险、绿色发展途径等方面的问题，为守护好世界上最后一方净土、建 设美丽的青藏高原作出新贡献 ${ }^{[21]}$ 。这充分反映出党中央对新时代自然资源综合科学考察 工作向深度考察和自然资源综合研究转变, 服务国家重大战略的期许。当前, 我国综合 科学考察数据平台日趋完善, 考察数据积累日益丰富, 已经具备了在综合科学考察基础 上开展自然资源综合研究的基本条件。在综合科学考察基础上, 除了形成科学考察报 告、基础数据集（库）、图件等传统考察成果外，通过深人开展自然资源综合研究，发现 自然资源重大科学问题和区域开发重大实践问题，提出有见地的资源科学学术思想和区 域开发重要建议，在资源科学理论和实践两个方向创新突破，将极大地提升自然资源综 合科学考察成果显示度，这是新时代自然资源综合科学考察工作的必然要求。 


\section{2 .2 综合科学考察国际化进程将加快}

在共同构建人类命运共同体和推进“一带一路”倡议背景下，自然资源综合科学考 察的国际化进程将明显加快。无论是 “天堑变通途” 的路桥项目, 还是 “地底两万里” 的油气管线，这些项目立项、建设及维护的基础都离不开严谨细致的地理、资源、生态 环境与社会经济等多学科跨国科学考察研究创新 ${ }^{[2]}$ 。2007年以来, 科技部先后启动国家 科技基础性工作专项重点项目 “中国北方及其毗邻地区综合科学考察” “澜沧江中下游与 大香格里拉地区科学考察” 两大跨国科学考察专项。2017年以后, 科技部先后启动国家 科技基础资源调查专项 “中蒙俄国际经济走廊多学科联合科学考察” “中巴经济走廊自然 灾害综合调查与评估” 等 “一带一路” 相关区域科学考察专项，有力地推动了新时期我 国自然资源综合科学考察工作的国际化，为国家全球化战略提供了基础科技支撑。“一带 一路” 框架下参与国家众多, 不同国家的发展阶段、发展诉求不同, 开展跨国科学考 察、摸清现状，将为“一带一路” 沿线国家合作共赢、共同发展提供更多科学支撑 ${ }^{[22]}$ 。 这其中, “一带一路” 重要经济走廊考察、极地科考和海洋科考将成为新时代自然资源综 合科学考察国际化的重要方向。

\section{2 .3 注重多学科综合考察与宏观微观结合调查}

从近年来科技部资助的国家重大科学考察和调查专项来看，考察对象的多学科性明 显增强，除了传统的自然和地学领域的考察外，尤其加强了对人口、疾病医学与健康等 人文领域的调查, 反映出社会经济发展对基础资源调查需求的紧迫性。在考察和调查的 深度上, 从传统面上宏观考察, 向点上重点调查和特定调查对象的微观调查明显加强。 在地学领域的科学考察工作也反映出多学科性、综合性、微观化的特征。以第二次青藏 高原综合科学考察研究工作为例, 青藏高原已经成为国际上地学、生物学、资源与环境 方面的研究热点和关键区域, 一方面要求拓宽研究领域, 从地球科学、生命科学、资源 环境科学、社会经济科学等多学科角度, 研究青藏高原形成、演化及其资源环境效应, 以及与全球环境变化的互动作用; 另一方面，要越来越多的与青藏高原地区可持续发展 相结合，为资源合理开发利用、环境保护、生态建设、经济发展、社会进步提供更多的 科学依据, 这又要求自然与人文领域的深度融合研究 ${ }^{[1]}$; 在研究的深度上, 要求在地学与 生物学、地学与信息科学、地学与社会科学之间, 应促进学科间的交叉、渗透和集成, 分子生物学、基因调查和微观个体的抽样调查得到更多关注。这是新时代自然资源综合 科学考察工作的重要特点之一。

\section{2 .4 科学考察技术趋于多样化、信息化、智能化与精准化}

(1) 基于 $5 \mathrm{G}$ 网络和人工智能技术的智慧化科学考察前景广阔。人工智能、无人机、 机器人以及重大极地、深海、深空探测技术和智能装备的成熟, 将极大地拓展科学考察 的领域, 提升人类获取未知领域信息和进一步认识自然的能力。 $5 \mathrm{G}$ 环境可实现天（卫星 遥感) 空（无人机等遥控设备）地（地面实况）整体集成一体化自然要素考察及其科学 数据的实时传输, 并实现虚拟现实和未来预测相结合。应用人工智能技术提高野外考察 装备智能化, 有助于多学科多资源联合协同化考察。人工智能是人脑的延长和扩充, 有 望实现多国专家实时语言文字互通，有助于破解跨国联合考察研究中的语言障碍等问 题。毫无疑问，信息网络技术、大数据、人工智能技术等新技术手段将在未来科学考察 中发挥不可替代的重要作用, 将推动科学考察更加精准、高效、快速、海陆并进、空天 一体。这是新时代自然资源综合科学考察工作的重要增长点。 
（2）多样化的科学考察技术将极大地提高科学考察研究的精准性。新时代将迎来新 一轮科技革命，信息科学、生命科学和物质科学的交叉领域将很可能是人类新科技革命 的重要突破口，科技创新和工程科学的发展将为科学考察技术革新带来前所未有的促进 作用。信息科学、空间技术和传感技术的发展，使得跨时空在线监测和空间调查更加智 慧、高效和灵活便捷，遥感监测、现场调查、生态网络定点监测和样本分析相结合，宏 观观测与微观检测技术相结合，将促进科学考察工作从定性向定量、由简单定量向精确 定量深化。这成为新时代自然资源综合科学考察工作的重大机遇。

(3) 即期静态考察向跨期动态考察转变提升科考成果可验证性。科学研究的精确化 要求科学考察从传统的即期静态考察向跨期动态考察和对比研究转变。一方面，上世纪 中后期我国开展的众多区域科学考察成果为新时期自然资源综合科学考察基础上的动态 对比研究提供了可能；另一方面，随着我国野外观测试验网络的完善和 “ $3 \mathrm{~S}$ ”技术的飞 速发展，定点动态观测和遥感监测将成为科学考察的重要手段，多期的动态考察将成为 常态，将推进我国科考工作从即期的静态考察向跨期、多期或随机的动态考察研究转 变, 这将极大地推进我国自然资源综合科学考察研究成果的可验证性和精确度。这是新 时代自然资源综合科学考察和研究工作的重要转向。

\section{2 .5 科学考察数据共享平台支撑将得到强化}

产出权威系统的科学数据、调查报告、科技资料、图集图件等基础性成果，并实现 开放共享，以推进基础学科发展、支撑科技创新活动、支撑国家宏观决策等是自然资源 综合科学考察工作的重要任务之一, 这离不开科学考察与数据共享平台支撑。“十三五” 时期，科技部启动国家科学数据平台优化调整工作，将原有数据类国家科技资源共享服 务平台优化调整为 20 个国家科学数据中心, 涵盖地球系统科学、人口与健康及各行业数 据共享平台（中心），明确科学考察数据共享平台在国家创新体系建设特别是国家科技创 新基地建设中具有不可替代的作用。数据共享平台的丰富将有助于科学考察数据的规范 采集和质量控制，并对获得的数据进行系统的收集、整理、加工，不断积累和综合集 成, 为相关学科深人研究打下坚实基础, 为政府科学决策提供可靠的数据支撑。这是新 时代我国自然资源综合科学考察工作再创佳绩的重要基础。

\subsection{6 科学考察人才培养尤其是国际人才培养成为紧迫需求将得到重视}

自然资源综合科学考察工作的开展和科考事业的延续关键是人才，依靠一批资源科 学、地理科学等多学科理论基础扎实、野外作业经验丰富、又精通现代信息技术的骨干 科考人员，而跨境科考受到语言障碍、风俗习惯、地缘关系的限制，对科考人员的素质 要求更高。加强科学考察人才培养和队伍建设是当务之急, 随着 “一带一路” 倡议的推 进，有关科技主管部门已经意识新时期科考人才尤其是跨国科考人才的重要性，科技 部、国家自然科学基金委近年来组织实施的人才计划和国际交流计划明显增多。结合我 国企业 “走出去” 跨国经营重大战略需要, 未来有望适时启动国际科考专项, 吸引国际 优秀人才参与到我国的科考事业，积极培养国际科考人才队伍，这是新时代我国自然资 源综合科学考察工作最迫切的任务之一。

\section{参考文献(References):}

[1] 孙鸿烈. 青藏高原科学考察研究的回顾与展望. 资源科学, 2000, 22(3): 6-8. [SUN H L. Review and prospect of scientific expedition on the Tibetan Plateau. Resources Science, 2000, 22(3): 6-8.]

[2] 郑度, 潘裕生. 喀喇昆仑山一昆仑山地区综合科学考察研究的新进展. 地球科学进展, 1991, 6(5): 94-98. [ZHENG D, 
PAN Y S. New progress of the comprehensive scientific expedition and research on the Karakorum Range- Kunlun Mountain Area. Advance in Earth Science, 1991, 6(5): 94-98.]

[3] 张莉, 张冬梅. 孙鸿烈谈第一次青藏高原综合科学考察. 科学通报, 2019, 64(27): 2763-2764. [ZHANG L, ZHANG D M. Honglie Sun: The first Tibetan Plateau scientific expedition and research. Chinese Science Bulletin, 2019, 64(27): 2763-2764.]

[4] 中国科学院开展第二次青藏高原综合科学考察. 中国科学院院刊, 2018, 33(z2): 131. [The second Tibetan Plateau comprehensive scientific expedition carried out by the Chinese Academy of Sciences. Bulletin of Chinese Acdemy of Sciences, 2018, 33(z2): 131.]

[5] 张冬梅, 张莉. 对话姚檀栋: 走进第二次青藏高原综合考察. 科学通报, 2019, 64(27): 2765-2769. [ZHANG D M, ZHANG L. Tandong Yao: The second Tibetan Plateau scientific expedition and research. Chinese Science Bulletin, 2019, 64(27): 2765-2769.]

[6] 李莹, 操戈, 邓卫哲. 中国热科院顺利完成南海生物资源一期科考. 农民日报, 2019, (5): 54. [LI Y, CAO G, DENG W Z. Chinese Academy of Thermal Sciences successfully completed the first phase of the South China Sea biological resources scientific research. World Tropical Agriculture Information, 2019, (5): 54.]

[7] 雷瑞波. 中国第9次北极科学考察简报. 极地研究, 2019, 62(1): 114-116. [LEI R B. Briefing of 9th Chinese National Arctic Research Expedition. Chinese Journal of Polar Research, 2019, 62(1): 114-116.]

[8] 杨洋, 董锁成, 李富佳, 等. 东北振兴与俄罗斯远东和贝加尔地区开发战略契合机制研究. 资源科学, 2019, 41(01): 43-52. [YANG Y, DONG S C, LI F J, et al. Study on the coordination mechanism between strategies of Northeast China revitalization and development of Russian Far East and Baikal region. Resources Science, 2019, 41(1): 43-52.]

[9] 赵玲. 中国南极科考五大成果. 中国科技奖励, 2017, (3): 28-29. [ZHAO L. Five achievements of China's Antarctic scientific research. China Awards for Science and Technology, 2017, (3): 28-29.]

[10] 董锁成, 孙九林. 中国北方及其毗邻地区综合科学考察综合报告. 北京: 科学出版社, 2016: 1-3. [DONG S C, SUN J L. Comprehensive Report of Integrated Scientific Survey in Northern China and Adjacent Area. Beijing: Science Press, 2016: 1-3.]

[11] 成升鬼, 沈镭, 徐增让. 澜沧江流域与大香格里拉地区科学考察综合研究. 北京: 科学出版社, 2015: 1-10. [CHENG S K, SHEN L, XU Z R. Comprehensive Research on the Scientific Survey of Lancang River Basin and Greater ShangriLa Region. Beijing: Science Press, 2015: 1-10.]

[12] 国家发展改革委, 外交部, 商务部. 推动共建丝绸之路经济带和 21 世纪海上丝绸之路的愿景与行动. 2015 年 3 月. [National Development and Reform Commission, Ministry of Foreign Affairs and Ministry of Commerce of the People's Republic of China, Vision and actions on jointly building Belt and Road, March 2015.]

[13] 习近平. “一带一路” 国际合作高峰论坛开幕主旨演讲, 2017 年 5 月 14 日, 北京. [XI J P. Opening Keynote Speech of Belt and Road Forum for International Cooperation, 14th May 2017, Beijing.]

[14] 李富佳, 董锁成, 原琳娜, 等. “一带一路”农业战略格局及对策. 中国科学院院刊, 2016, 31(6): 678-688. [LI F J, DONG S C, YUAN L N, et al. Study on agriculture patterns and strategy of the Belt and Road. Bulletin of Chinese Academy of Sciences, 2016, 31(6): 678-688.]

[15] 杜德斌, 马亚华. “一带一路”: 中华民族复兴的地缘大战略. 地理研究, 2015, 34(6): 1005-1014. [DU D B, MA Y H. One Belt and One Road: The grand geo-strategy of China's rise. Geographical Research, 2015, 34(6): 1005-1014.]

[16] 王礼茂, 牟初夫, 陆大道. 地缘政治演变驱动力变化与地缘政治学研究新趋势. 地理研究, 2016, 35(1): 3-13. [WANG L M, MU C F, LU D D. Changes in driving forces of geopolitical evolution and the new trends in geopolitics studies. Geographical Research, 2016, 35(1): 3-13.]

[17] 杨志荣. 北极航道全年开通后世界地缘战略格局的变化研究. 国防科技, 2015, 36(4): 7-11. [YANG Z R. Changes in world geo-strategic situation and countermeasures after the all-year-open of arctic channel. National Defense Science \& Technology, 2015, 36(4): 7-11.]

[18] 孙鸿烈, 成升鬼, 封志明. 60 年来的资源科学: 由资源综合考察到资源科学综合研究. 自然资源学报, 2010, 25(9): 1414-1423. [SUN H L, CHENG S K, FENG Z M. From integrated surveys of natural resource to comprehensive research of resources sciences over 60 years. Journal of Natural Resources, 2010, 25(9): 1414-1423.]

[19] 孙九林. 中国南方能源资源开发战略探讨. 自然资源学报, 1990, 5(2): 116-125. [SUN J L. Exploration on the development strategy of the energy resources in the south of China. Journal of Natural Resources, 1990, 5(2): 116-125.] 
[20] 中华人民共和国科学技术部. 关于发布科技基础资源调查专项 2018 年度项目指南的通知(国科发基[2017]380 号), http://www.most.gov.cn/mostinfo/xinxifenlei/fgzc/gfxwj/gfxwj2017/201712/t20171213_136772.htm, 2017- 12- 07. [Ministry of Science and Technology. Announcement on the release of the 2018 project guide for the special scientific and technological basic resources survey, http://www.most.gov.cn/mostinfo/xinxifenlei/fgzc/gfxwj/gfxwj2017/201712/ t20171213_136772.htm, 2017-12-07.]

[21] 习近平. 致中国科学院青藏高原综合科学考察研究队的贺信. http://www.cas.cn/gj/201708/t20170819_4611607.shtml, 2017-08-19. [XI J P. Congratulatory letter to the Qinghai-Tibet Plateau comprehensive scientific investigation team of the Chinese Academy of Sciences, http://www.cas.cn/gj/201708/t20170819_4611607.shtml, 2017-08-19.]

[22] 董锁成. 跨国地理科考: “一带一路”新支撑. 光明日报, 2018-01-24(14). [DONG S C. Transnational geography research: New support for the "Belt and Road". Guangming Daily, 2018-01-24(14).]

\title{
Challenges and prospects of natural resources integrated surveys and researches in the New Era of China
}

\author{
SUN Jiu-lin ${ }^{1,2}$, DONG Suo-cheng ${ }^{1,2}$, LI Ze-hong ${ }^{1,2}$, LI Yu ${ }^{1,2}$, LI Fu-jia ${ }^{1,2}$ \\ (1. Institute of Geographic Sciences and Natural Resources Research, CAS, Beijing 100101, China; \\ 2. University of Chinese Academy of Sciences, Beijing 100049, China)
}

\begin{abstract}
The integrated survey of natural resources is a basic scientific and technological work, which plays an important role in supporting the national economic and social development. In the 21st century, China's integrated surveys and researches of natural resources have gradually recovered from the trough, but still facing many challenges such as the discontinuation of scientific research talents, insufficient funding support, the difficulty of multinational investigation organizations, and the lack of outstanding research results. This article summarizes the latest progresses of China's integrated survey and research works from the perspective of territorial scope, team composition, technical measures, and impact of achievements. It looks forward to the New Era of China and proposes six development trends of the integrated surveys and researches as follows: The integrated surveys will transform to comprehensive researches on natural resources; the internationalization of surveys will accelerate; key points will focus on multidisciplinary comprehensive investigations and macro-micro integrated surveys; inspection techniques will be more diversified, intelligent, and targeted; the support capabilities of scientific investigation information and data sharing platforms will be stronger; the training of scientific talents will be strengthened.
\end{abstract}

Keywords: natural resources; integrated survey and research; the New Era; progress; challenge; prospect 